\title{
Pneumoperitoneum due to a necrotic cavity wall perforation seen at endoscopic necrosectomy
}

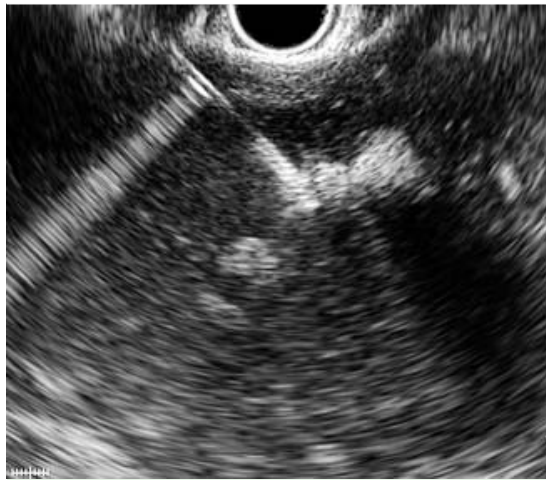

Fig. 1 Image showing the endoscopic ultrasound (EUS)-guided puncture of a walled-off area of necrosis (WON).

A 55-year old man with a large infected walled-off area of pancreatic necrosis (WON) was referred to us for endoscopic drainage. Endoscopic ultrasound (EUS) revealed a significant amount of solid debris. Under EUS guidance, the WON was punctured ( Fig.1) and, after tract dilation, two 10-Fr double-pigtail stents and a nasocystic catheter were placed to drain the cavity. The patient's pain improved but his fever persisted. A week later, the nasocystic catheter was removed and the stents were exchanged for three $10-$ Fr stents. Despite three sessions of stent exchange, his fever persisted and a computed tomography (CT) scan revealed a persistent collection with air pockets that had formed because of the drainage of liquid debris ( $\bullet$ Fig. 2 ).

After interdisciplinary consultation, an endoscopic necrosectomy was performed ( Fig. 3 a) and solid necrotic material was removed using Dormia and net baskets. After the procedure had been completed, a small rent was noticed in the wall of the WON ( $\bullet$ Fig.3b). Four 10-Fr doublepigtail transmural stents were placed in the cavity. Post-necrosectomy abdominal radiographs showed air under the dome of the diaphragm ( $\bullet$ Fig.4). The patient was experiencing mild abdominal discomfort, but no guarding or rigidity on examination, so a nasojejunal tube was also placed for enteral feeding. A contrast-enhanced CT scan confirmed the presence of a pneumoperitoneum with minimal ascites and an air-filled WON

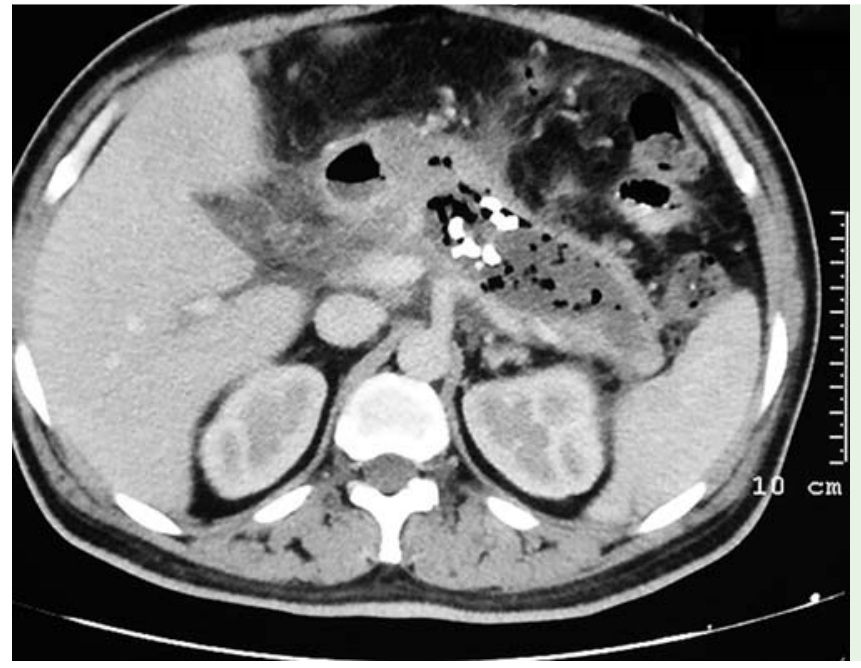

Fig. 2 Computed tomography (CT) scan showing persistence of the collection and the presence of air pockets after transmural drainage had been performed.
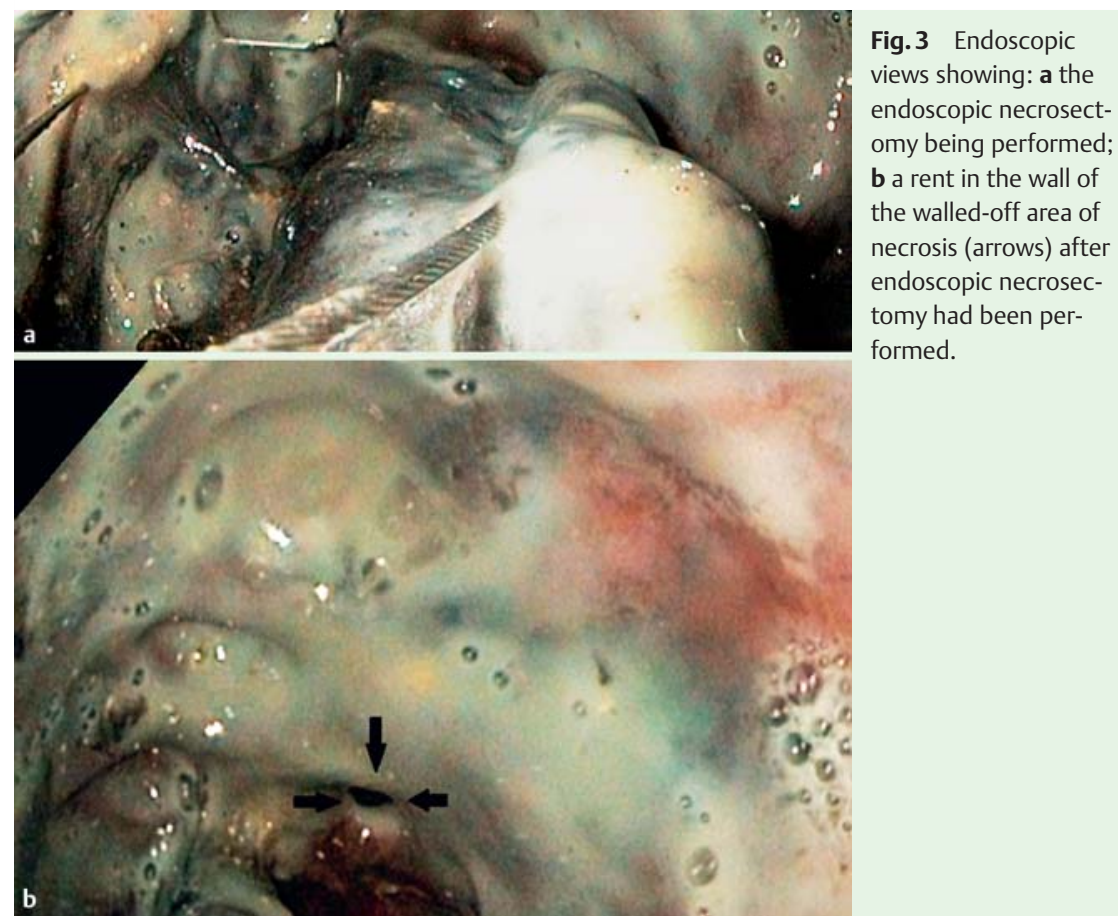
formed.

cavity ( $\bullet$ Fig. 5), but there was no leakage of enteral contrast.

The patient's fever resolved and a repeat abdominal radiograph taken on day 7 showed the disappearance of the air under the diaphragm. The nasojejunal tube was removed, the stents were exchanged for two 10-Fr 3-cm stents, and the patient was discharged.

Endoscopic treatment of a WON involves using more aggressive techniques such as dilation of a large tract, placement of multiple or metal stents, aggressive irrigation, and direct debridement of necrotic tissue [1]. Direct endoscopic necrosectomy is a more aggressive technique for endoscopic drainage of a WON that is associated with an increased frequency of complications, including pneumoperitoneum and bleeding [2].

Endoscopy_UCTN_Code_CPL_1AL_2AD 


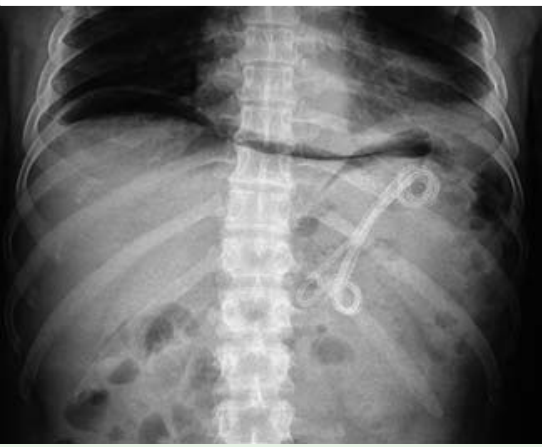

Fig. 4 Abdominal radiograph showing air under the diaphragm, consistent with a pneumoperitoneum, and the transmural pigtail stents in situ.

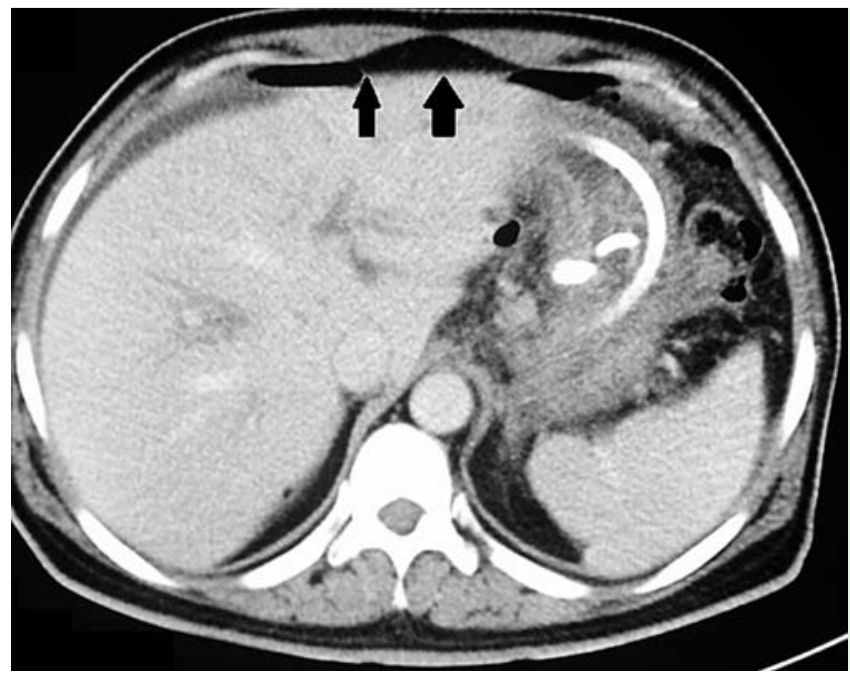

Fig. 5 Computed tomography (CT) scan showing intraperitoneal air (arrows), consistent with a pneumoperitoneum, but minimal ascites, and the airfilled cavity from the walled-off area of necrosis.

\section{Competing interests: None}

\section{Surinder S. Rana, Deepak Gunjan, Deepak K. Bhasin}

Department of Gastroenterology, Post Graduate Institute of Medical Education and Research (PGIMER), Chandigarh, India

\section{References}

1 Rana SS, Bhasin DK, Rao C et al. Non-fluoroscopic endoscopic ultrasound-guided transmural drainage of symptomatic non-bulging walled-off pancreatic necrosis. Dig Endosc 2013; 25: 47-52

2 Gardner TB, Coelho-Prabhu N, Gordon SR et al. Direct endoscopic necrosectomy for the treatment of walled-off pancreatic necrosis: results from a multicenter U.S. series. Gastrointest Endosc 2011; 73: 718-726

\section{Bibliography}

DOI http://dx.doi.org/

10.1055/s-0034-1392506

Endoscopy 2015; 47: E391-E392

(c) Georg Thieme Verlag KG

Stuttgart · New York

ISSN 0013-726X

\section{Corresponding author}

\section{Surinder Singh Rana, MD}

Department of Gastroenterology

Postgraduate Institute of Medical Education and Research (PGIMER)

Chandigarh - 160012

India

Fax: 91-172-2744401

drsurinderrana@yahoo.co.in

sonalisurinder@yahoo.co.in 